MSC 93E12, 65G40

DOI: $10.14529 / \mathrm{mmp200213}$

\title{
CONVERGENCE ANALYSIS OF THE GUARANTEED PARAMETER ESTIMATION ALGORITHM FOR MODELS OF ONE-DIMENSIONAL CHAOTIC SYSTEMS
}

\author{
A.S. Sheludko, South Ural State University, Chelyabinsk, Russian Federation \\ sheludkoas@susu.ru
}

This paper considers the parameter estimation problem for models of one-dimensional chaotic systems. The guaranteed algorithm is proposed in the context of set-membership approach, which assumes that only intervals of possible values are known for the uncertain variables in the model (initial condition, parameter and measurement errors). The algorithm recursively computes the interval estimates of the parameter at every time step. If the prior information is correct, found interval estimates always contain the true value of the parameter. For certain models of measurement errors the result of the algorithm is the exact value of the parameter (the final interval estimate contains a single point). The goal of this study is to derive conditions under which the guaranteed algorithm improves the interval estimate of the parameter.

Keywords: chaotic system; nonlinear model; parameter estimation; interval estimate.

\section{Introduction}

Parameter estimation is an important problem in chaos-based applications in signal processing and time series modelling [1,2]. This paper considers the estimation problem for models of one-dimensional chaotic systems. The dynamic and measurement model is

$$
\left\{\begin{array}{l}
x_{k}=f\left(x_{k-1}, \lambda\right), \\
y_{k}=x_{k}+v_{k},
\end{array}\right.
$$

where $f$ is chaotic map [3], $x_{k}$ is the state variable, $\lambda$ is the model parameter, $y_{k}$ is the measured value, $v_{k}$ is the additive measurement error, and $k$ is the number of time step. The problem is to estimate the unknown parameter $\lambda$ from measurements $y_{k}, k=1,2, \ldots, N$, where $N$ is the number of measurements. Note, that the initial condition $x_{0}$ is also unknown, since it defines the value of the state variable $x_{k}$ at time step $k$ :

$$
x_{k}=f^{k}\left(x_{0}, \lambda\right)=\underbrace{f(f(f \ldots f}_{k}\left(x_{0}, \lambda\right) \ldots)) .
$$

The most common estimation technique is the least squares method (LSM) and its modifications, such as multiple shooting approach and combination with backward iteration $[2,4]$. From the viewpoint of real-time processing, the most common is the use of the Kalman filter (KF) modifications for nonlinear systems (for example, widely used unscented KF) [1,4].

The LSM and KF are based on the probabilistic description of the uncertain variables, and measurement errors are assumed to be Gaussian. In some cases, these techniques can provide accurate results even if the probabilistic assumptions are not satisfied. However, all mentioned techniques face difficulties related to the nonlinear properties of chaotic systems (it is discussed in details in $[5,6]$ ). 
Recently in [5], the guaranteed algorithm (GA) was developed in the context of set-membership approach [7]. In past decades, this approach has become a widespread technique for nonlinear estimation $[8,9]$. The GA is a recursive procedure that based on the interval analysis $[10,11]$.

\section{Guaranteed Algorithm}

Suppose that the initial condition $x_{0}$, parameter $\lambda$ and measurement error $v_{k}$ are bounded by intervals:

$$
x_{0} \in X_{0}=\left[\underline{x}_{0} ; \bar{x}_{0}\right], \lambda \in \Lambda_{0}=\left[\underline{\lambda}_{0} ; \bar{\lambda}_{0}\right], v_{k} \in V_{k}=\left[\underline{v}_{k} ; \bar{v}_{k}\right] .
$$

Thus, in contrast to the LSM and KF, it is not necessary to know the statistical properties of measurement errors. Further in this paper, it is assumed that for all $k=1,2, \ldots, N$ the interval estimates of measurement errors are equal:

$$
V_{1}=\ldots=V_{N}=[\underline{v} ; \bar{v}] .
$$

As mentioned above, the GA is a recursive procedure. Suppose that $X_{k-1}, \Lambda_{k-1}$ are the interval estimates of the state variable and parameter, respectively, which are computed after $k-1$ iterations. The interval estimates $X_{k}, \Lambda_{k}$ at time step $k$ are defined by the following scheme.

Step 1. Computation of the predicted state set $X_{k / k-1}$ :

$$
X_{k / k-1}=f\left(X_{k-1}, \Lambda_{k-1}\right) .
$$

Here $f$ is considered as an interval map:

$$
f\left(X_{k-1}, \Lambda_{k-1}\right)=\left\{u \mid u=f(x, \lambda), x \in X_{k-1}, \lambda \in \Lambda_{k-1}\right\} .
$$

Step 2. Computation of the consistent state set $Y_{k}$ :

$$
Y_{k}=\left\{x \mid x=y_{k}-v, v \in V_{k}\right\}=\left[y_{k}-\bar{v} ; y_{k}-\underline{v}\right] .
$$

Step 3. Computation of the interval estimate $X_{k}$ of the state variable $x_{k}$ :

$$
X_{k}=X_{k / k-1} \cap Y_{k} .
$$

Step 4. Computation of the interval estimate $\Lambda_{k} \subseteq \Lambda_{k-1}$ of the parameter $\lambda$ :

$$
\Lambda_{k}=\left\{\lambda \in \Lambda_{k-1} \mid f\left(X_{k-1}, \lambda\right) \cap X_{k} \neq \varnothing\right\},
$$

where

$$
f\left(X_{k-1}, \lambda\right)=\left\{u \mid u=f(x, \lambda), x \in X_{k-1}\right\} .
$$

The steps $1-4$ is repeated for $k=1,2, \ldots, N$. If the prior interval estimates (1) are correct, the algorithm produces guaranteed results. It means that at every time step $k$ found interval estimates $X_{k}, \Lambda_{k}$ always contain the true values $x_{k}^{*}, \lambda^{*}$ of the state variable $x_{k}$ and parameter $\lambda$, respectively:

$$
x_{k}^{*} \in X_{k}=\left[\underline{x}_{k} ; \bar{x}_{k}\right], \lambda^{*} \in \Lambda_{k}=\left[\underline{\lambda}_{k} ; \bar{\lambda}_{k}\right] .
$$

The effectiveness of the GA, its modification in the backward time direction, and some useful applications have been studied previously in $[6,12]$. This paper studies the convergence of the GA for certain models of measurement errors. 


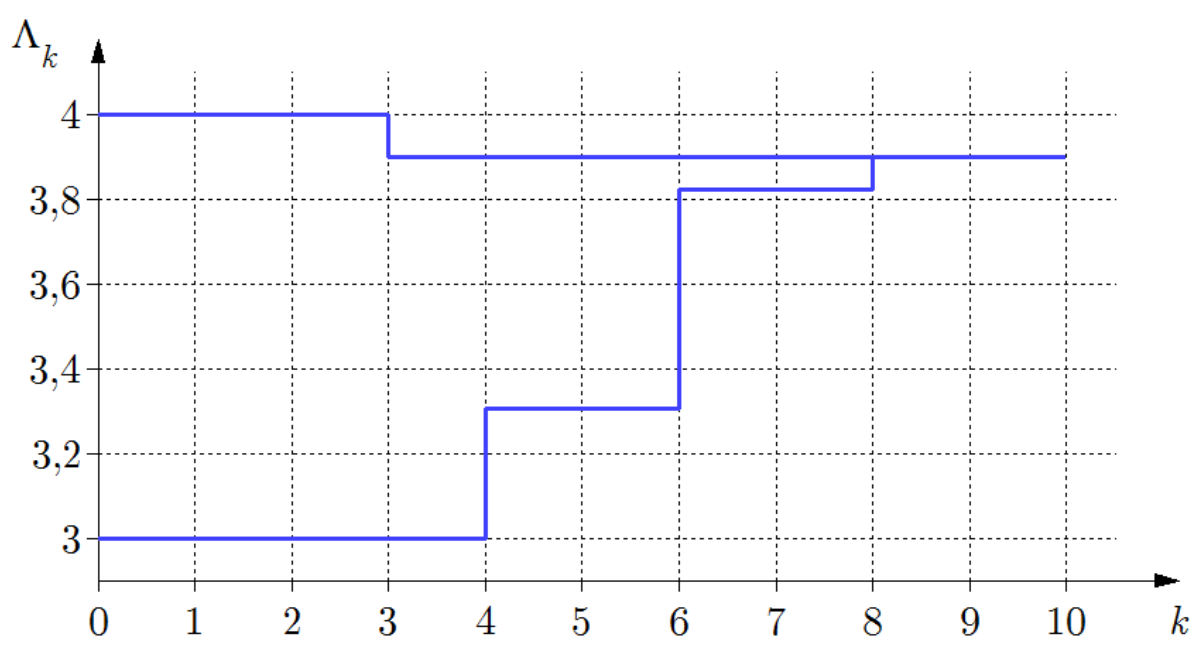

Fig. 1. Bounds of the interval estimate of the parameter (Example 1)

\section{Numerical Simulation}

Consider the performance of the GA for parameter estimation of the logistic map

$$
x_{k}=f\left(x_{k-1}, \lambda\right)=\lambda x_{k-1}\left(1-x_{k-1}\right) .
$$

The true value of the parameter is $\lambda^{*}=3,9$, and the initial condition is $x_{0}^{*}=0,4$. The following interval estimates are used as the input of the GA:

$$
X_{0}=[0 ; 0,5], \Lambda_{0}=[3 ; 4], V_{1}=\ldots=V_{N}=[-0,2 ; 0,2] .
$$

In general, the accuracy of guaranteed estimation depends on the model of measurement errors $[13,14]$. It was noted in [5] that the GA improves the interval estimate $\Lambda_{k}$ when the measurement error $v_{k}$ is close to the bounds of its interval estimate $V_{k}$. To study this feature in more detail, consider the following two examples.

Example 1. Let $v_{k}=0,2 \cos \pi k$. The output of the GA is shown in Fig. 1. In this example, the interval estimate of the parameter $\lambda$ was specified at $k=3,4,6,8$.

Example 2. Let $v_{k}=0,2 \cos \pi\left\lceil\frac{k}{5}\right\rceil$. The output of the GA is shown in Fig. 2. In this example, the interval estimate of the parameter $\lambda$ was specified at $k=2,6,7$.

In both examples the final interval estimate contains a single point. This point is the true value $\lambda^{*}$ of the parameter $\lambda$. Thus, it is useful to derive conditions under which the GA improves the interval estimate of the parameter $\lambda$.

\section{Convergence Analysis}

Suppose that $k-1$ iterations of the GA are completed, and at time step $k$ the predicted state set $X_{k / k-1}=\left[\underline{x}_{k / k-1} ; \bar{x}_{k / k-1}\right]$ is computed.

Theorem 1. One of the bounds $\underline{\lambda}_{k+1}, \bar{\lambda}_{k+1}$ of the interval estimate $\Lambda_{k+1}$ is equal to the true value $\lambda^{*}$ of the parameter $\lambda$ if the following conditions are satisfied.

1. The map $f(x, \lambda)$ is monotone increasing as a function of $x$ in the predicted state set $X_{k / k-1}$. 


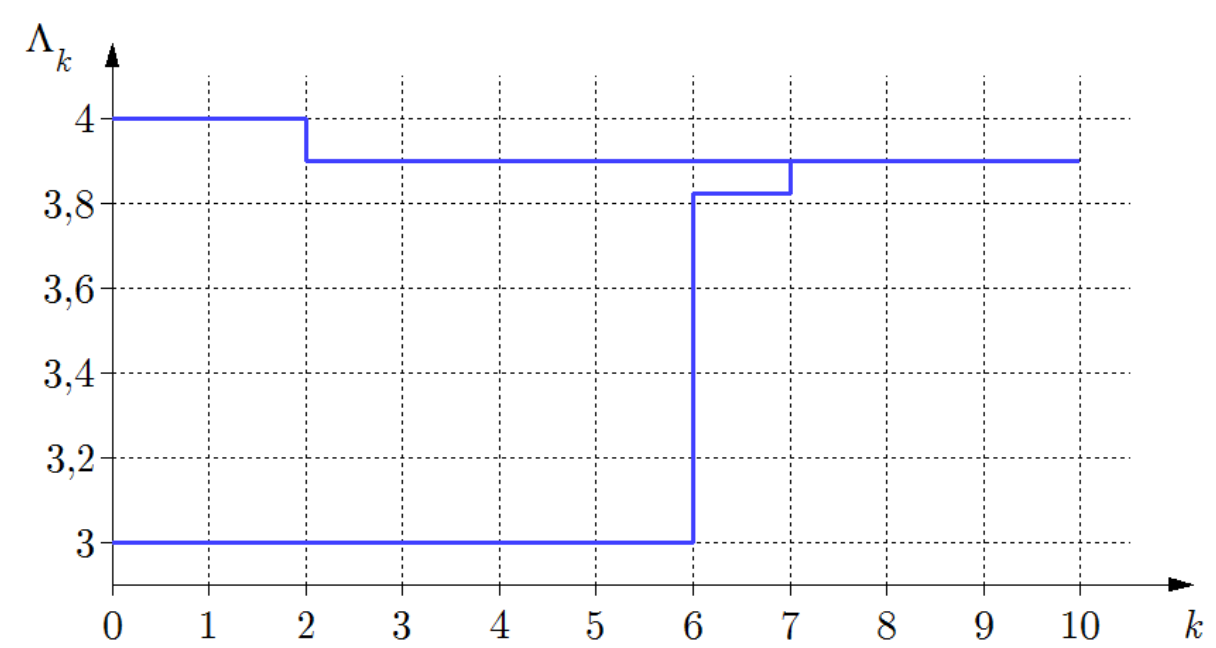

Fig. 2. Bounds of the interval estimate of the parameter (Example 2)

2. The map $f(x, \lambda)$ is monotone increasing as a function of $\lambda$ in the set $\Lambda_{k-1}$.

3. The measurement errors $v_{k}$ and $v_{k+1}$ are equal to the opposite bounds of the interval of possible values.

Proof. Suppose that the measurement errors $v_{k}$ and $v_{k+1}$ are equal to the upper and lower bounds of the interval of possible values, respectively: $v_{k}=\bar{v}, v_{k+1}=\underline{v}$.

Consider the computations at time step $k$. The measured value is $y_{k}=x_{k}^{*}+\bar{v}$, where $x_{k}^{*}$ denotes the true value of the state variable. Then the consistent state set $Y_{k}(3)$ is

$$
Y_{k}=\left[y_{k}-\bar{v} ; y_{k}-\underline{v}\right]=\left[x_{k}^{*}+\bar{v}-\bar{v} ; x_{k}^{*}+\bar{v}-\underline{v}\right]=\left[x_{k}^{*} ; x_{k}^{*}+\bar{v}-\underline{v}\right] .
$$

Thus, the interval estimate $X_{k}(4)$ of the state variable $x_{k}$ is

$$
X_{k}=X_{k / k-1} \cap Y_{k}=\left[\underline{x}_{k / k-1} ; \bar{x}_{k / k-1}\right] \cap\left[x_{k}^{*} ; x_{k}^{*}+\bar{v}-\underline{v}\right]=\left[x_{k}^{*} ; a\right],
$$

where $a=\min \left\{\bar{x}_{k / k-1}, x_{k}^{*}+\bar{v}-\underline{v}\right\}$. Note that, according to the condition of the theorem, the map $f$ is monotone increasing as a function of $x$ in $X_{k} \subseteq X_{k / k-1}$.

Now consider the computations at time step $k+1$. The predicted state set $X_{k+1 / k}(2)$ is

$$
X_{k+1 / k}=f\left(X_{k}, \Lambda_{k}\right)=\left[f\left(x_{k}^{*}, \underline{\lambda}_{k}\right) ; f\left(a, \bar{\lambda}_{k}\right)\right],
$$

since the map $f$ is monotone increasing in both arguments. The corresponding measured value is $y_{k+1}=x_{k+1}^{*}+\underline{v}$, and the consistent state set $Y_{k+1}(3)$ is

$$
Y_{k+1}=\left[y_{k+1}-\bar{v} ; y_{k+1}-\underline{v}\right]=\left[x_{k+1}^{*}+\underline{v}-\bar{v} ; x_{k+1}^{*}+\underline{v}-\underline{v}\right]=\left[x_{k+1}^{*}+\underline{v}-\bar{v} ; x_{k+1}^{*}\right] \text {. }
$$

Thus, the interval estimate $X_{k+1}(4)$ of the state variable $x_{k+1}$ is

$$
\begin{aligned}
X_{k+1}=X_{k+1 / k} \cap Y_{k+1} & =\left[f\left(x_{k}^{*}, \underline{\lambda}_{k}\right) ; f\left(a, \bar{\lambda}_{k}\right)\right] \cap\left[x_{k+1}^{*}+\underline{v}-\bar{v} ; x_{k+1}^{*}\right]= \\
& =\left[b ; x_{k+1}^{*}\right]=\left[b ; f\left(x_{k}^{*}, \lambda^{*}\right)\right],
\end{aligned}
$$

where $b=\max \left\{f\left(x_{k}^{*}, \underline{\lambda}_{k}\right), x_{k+1}^{*}+\underline{v}-\bar{v}\right\}$. 
According to (5), the set $\Lambda_{k+1}$ consist of all parameter values $\lambda \in \Lambda_{k}$ such that

$$
f\left(X_{k}, \lambda\right) \cap X_{k+1}=\left[f\left(x_{k}^{*}, \lambda\right) ; f(a, \lambda)\right] \cap\left[b ; f\left(x_{k}^{*}, \lambda^{*}\right)\right] \neq \varnothing .
$$

Hence $f\left(x_{k}^{*}, \lambda\right) \leq f\left(x_{k}^{*}, \lambda^{*}\right)$. Since the map $f$ as a function of $\lambda$ is monotone increasing, it follows that $\lambda \leq \lambda^{*}$. Thus, $\bar{\lambda}_{k+1}=\lambda^{*}$.

The proof is similar if $v_{k}=\underline{v}, v_{k+1}=\bar{v}$. In this case, at time step $k+1$ the lower bound $\underline{\lambda}_{k+1}$ of the interval estimate $\Lambda_{k+1}$ is equal to the true value $\lambda^{*}$ of the parameter $\lambda$ : $\underline{\lambda}_{k+1}=\lambda^{*}$.

Theorem 2. One of the bounds $\underline{\lambda}_{k+1}, \bar{\lambda}_{k+1}$ of the interval estimate $\Lambda_{k+1}$ is equal to the true value $\lambda^{*}$ of the parameter $\lambda$ if the following conditions are satisfied.

1. The map $f(x, \lambda)$ is monotone decreasing as a function of $x$ in the predicted state set $X_{k / k-1}$.

2. The map $f(x, \lambda)$ is monotone increasing as a function of $\lambda$ in the set $\Lambda_{k-1}$.

3. The measurement errors $v_{k}$ and $v_{k+1}$ are equal to one of the bounds of the interval of possible values.

Proof. The scheme of the proof is similar to the previous theorem.

Acknowledgements. The work was supported by Act 211 Government of the Russian Federation, contract no. 02.A03.21.0011.

\section{References}

1. Feng J.C., Tse C.K. Reconstruction of Chaotic Signals with Applications to Chaos-Based Communications. Singapore, World Scientific, 2008. DOI: 10.1142/6585

2. Bezruchko B.P., Smirnov D.A. Extracting Knowledge from Time Series. An Introduction to Nonlinear Empirical Modeling. Springer, 2010. DOI: 10.1007/978-3-642-12601-7

3. Kolesov A.Yu., Rozov N.Kh. On the Definition of Chaos. Russian Mathematical Surveys, 2009, vol. 64, no. 4, pp. 701-744.

4. Voss H.U., Timmer J., Kurths J. Nonlinear Dynamical System Identification from Uncertain and Indirect Measurements. International Journal of Bifurcation and Chaos, 2004, vol. 14, no. 6, pp. 1905-1933. DOI: 10.1142/S0218127404010345

5. Sheludko A.S., Shiryaev V.I. [The Algorithm of Guaranteed Parameter Estimation for One-Dimensional Chaotic Map]. Information Technologies, 2015, vol. 21, no. 1, pp. 30-34. (in Russian)

6. Sheludko A.S. [Guaranteed Parameter Estimation for Discrete-Time Chaotic Systems]. Bulletin of the South Ural State University. Series: Computational Mathematics and Software Engineering, 2018, vol. 7, no. 1. pp. 25-39. (in Russian) DOI: 10.14529/cmse180103

7. Kurzhanskii A.B., Furasov V.D. Identification of Nonlinear Processes: Guaranteed Estimates. Automation and Remote Control, 1999, vol. 60, no. 6, pp. 814-828.

8. Raissi T., Ramdani N., Candau Y. Set Membership State and Parameter Estimation for Systems Described by Nonlinear Differential Equations. Automatica, 2004, vol. 40, no. 10, pp. 1771-1777. DOI: 10.1016/j.automatica.2004.05.006

9. Abdallah F., Gning A., Bonnifait P. Box Particle Filtering for Nonlinear State Estimation Using Interval Analysis. Automatica, 2008, vol. 44, no. 3, pp. 807-815. DOI: 10.1016/j.automatica.2007.07.024 \& Computer Software (Bulletin SUSU MMCS), 2020, vol. 13, no. 2, pp. 144-150 
10. Jaulin L., Kieffer M., Didrit O., Walter E. Applied Interval Analysis. Springer, 2001. DOI: $10.1007 / 978-1-4471-0249-6$

11. Shary S.P. A New Technique in Systems Analysis under Interval Uncertainty and Ambiguity. Reliable Computing, 2002, vol. 8, no. 5, pp. 321-418. DOI: $10.1023 /$ A:1020505620702

12. Sheludko A.S. Approximation of the Solution Set for a System of Nonlinear Inequalities for Modelling a One-Dimensional Chaotic Process. Bulletin of the South Ural State University. Series: Mathematical Modelling, Programming and Computer Software, 2018, vol. 11, no. 1, pp. 152-157. DOI: $10.14529 / \mathrm{mmp} 180114$

13. Ananyev B.I., Shiryaev V.I. Determining the Worst Signals in Guaranteed Estimation Problems. Automation and Remote Control, 1987, no. 3, pp. 49-58.

14. Shiryaev V.I., Podivilova E.O. Set-Valued Estimation of Linear Dynamical System State When Disturbance is Decomposed as a System of Functions. Procedia Engineering, 2015, vol. 129, pp. 252-258. DOI: 10.1016/j.proeng.2015.12.045

Received November 7, 2019

УДК 519.7

DOI: $10.14529 / \mathrm{mmp} 200213$

\section{ИССЛЕДОВАНИЕ СХОДИМОСТИ АЛГОРИТМА ГАРАНТИРОВАННОГО ОЦЕНИВАНИЯ ПАРАМЕТРОВ МОДЕЛЕЙ ОДНОМЕРНЫХ ХАОТИЧЕСКИХ СИСТЕМ}

A.C. Шелудъко, Южно-Уральский государственный университет, г. Челябинск, Российская Федерация

Рассматривается задача оценивания параметров моделей одномерных хаотических систем. Применение гарантированного подхода предполагает представление априорной информации о неизвестных переменных в модели (начальном условии, параметре и ошибках измерений) только в виде интервалов возможных значений. Предложенный алгоритм гарантированного оценивания представляет собой рекуррентную процедуру вычисления интервальных оценок параметра в каждый момент времени. При корректной априорной информации полученные интервальные оценки всегда содержат истинное значение параметра. Для некоторых моделей ошибок измерений результатом является точное значение параметра (интервальная оценка содержит единственное значение). Целью данной работы является формулировка и доказательство условий, при которых на очередной итерации алгоритма происходит уточнение интервальной оценки параметра.

Ключевые слова: хаотическая система; нелинейная модель; оценивание параметров; интервальная оченка.

\section{Литература}

1. Feng, J.C. Reconstruction of Chaotic Signals with Applications to Chaos-Based Communications / J.C. Feng, C.K. Tse. - Singapore: World Scientific, 2008.

2. Bezruchko, B.P. Extracting Knowledge from Time Series. An Introduction to Nonlinear Empirical Modeling / B.P. Bezruchko, D.A. Smirnov. - Springer, 2010.

3. Колесов, А.Ю. К вопросу об определении хаоса / А.Ю. Колесов, Н.Х. Розов // Успехи математических наук. - 2009. - Т. 64, № 4. - С. 125-172. 
4. Voss, H.U. Nonlinear Dynamical System Identification from Uncertain and Indirect Measurements / H.U. Voss, J. Timmer, J. Kurths // International Journal of Bifurcation and Chaos. - 2004. - V. 14, № 6. - P. 1905-1933.

5. Шелудько, А.С. Алгоритм гарантированного оценивания параметра одномерного хаотического отображения / А.С. Шелудько, В.И. Ширяев // Информационные технологии. - 2015. - T. 21, № 1. - С. 30-34.

6. Шелудько, А.С. Гарантированное оценивание параметров дискретных моделей хаотических процессов / А.С. Шелудько // Вестник ЮУрГУ. Серия: Вычислительная математика и информатика. - 2018. - Т. 7, № 1. - С. 25-39.

7. Куржанский, А.Б. Идентификация нелинейных процессов - гарантированные оценки / А.Б. Куржанский, В.Д. Фурасов // Автоматика и телемеханика. - 1999. - № 6. C. $70-87$.

8. Raissi, T. Set Membership State and Parameter Estimation for Systems Described by Nonlinear Differential Equations / T. Raissi, N. Ramdani, Y. Candau // Automatica. 2004. - V. 40, № 10. - P. 1771-1777.

9. Abdallah, F. Box Particle Filtering for Nonlinear State Estimation Using Interval Analysis / F. Abdallah, A. Gning, P. Bonnifait // Automatica. - 2008. - V. 44, № 3. - P. 807-815.

10. Jaulin, L. Applied Interval Analysis / L. Jaulin, M. Kieffer, O. Didrit, E. Walter. - Springer, 2001.

11. Shary, S.P. A New Technique in Systems Analysis Under Interval Uncertainty and Ambiguity / S.P. Shary // Reliable Computing. - 2002. - V. 8, № 5. - P. 321-418.

12. Шелудько А.С. Аппроксимация множества решений системы нелинейных неравенств при моделировании одномерного хаотического процесса / А.С. Шелудько // Вестник ЮУрГУ. Серия: Математическое моделирование и программирование. - 2018. - Т. 11, № 1. - C. $152-157$.

13. Ананьев, Б.И. Определение наихудших сигналов в задачах гарантированного оценивания / Б.И. Ананьев, В.И. Ширяев // Автоматика и телемеханика. - 1987. - № 3. C. $49-58$.

14. Shiryaev, V.I. Set-Valued Estimation of Linear Dynamical System State When Disturbance is Decomposed as a System of Functions / V.I. Shiryaev, E.O. Podivilova // Procedia Engineering. - 2015. - V. 129. - P. 252-258.

Антон Сергеевич Шелудько, ассистент, кафедра «Прикладная математика и программирование», Южно-Уральский государственный университет (г. Челябинск, Российская Федерация), sheludkoas@susu.ru.

Поступила в редакцию 7 ноября 2019 г. 